Acta medico-historica Rigensia (2016) X:288-300

DOI: 10.25143/amhr.2016.X.17

М. П. Кузыбаева

\title{
Дары и дарители медицинских музеев России в первой половине XIX века
}

Возникновение и деятельность медицинских музеев в имперской России до недавнего времени оставались малоизученны. ${ }^{1}$

Проблемы формирования, состав фондовых собраний, источники пополнения коллекций были фрагментарно освещены:

- в публикациях об истории высших медицинских учреждений страны, ${ }^{2}$

${ }_{1}^{1}$ Кузыбаева М. П. Медицинские музеи России: становление и место в музейном мире (XVIII - первая треть XX в.) // Дисс. на соискание ученой степени кандидата исторических наук. - Москва: РГГУ, 2011. - 298 с.

2 Указатель Императорского Московского университета или краткое описание кабинетов и других заведений, находящихся при университете, с показанием всего достопримечательного в оных. - Москва, 1826. - 131 с.; История Военно-медицинской (бывшей Медико-Хирургической) Академии за сто лет, 1798-1898 / Под ред. профессора Н. П. Ивановского. - СПб., 1898; Ильин Л. Краткий исторический очерк кафедры фармации и фармацевтического отделения Императорской Военно-Медицинской Академии. - Спб., 1899; Ландшевский А. Исторический очерк кафедры академической хирургической клиники Императорской Военно-медицинской (бывшей Медико-Хирургической Академии, 1798-1898) // Диссертация на степень доктора медицины. СПб., 1898. - 345 с.; Таренецкий А. И. Кафедра и музей нормальной анатомии при Императорской Военно-Медицинской (бывшей МедикоХирургической) Академии в Санкт-Петербурге за 100 лет: Исторический очерк. - СПб., 1895. - 343 с. 
- в отдельных работах музеологов, ${ }^{3}$

- в отдельных работах историков медицины. ${ }^{4}$

Основы музейной деятельности, заложенные в эпоху Петра Великого, на протяжении XVIII века совершенствовались и развивались. Это проявилось, прежде всего, в росте общего количества музеев естественно-научного профиля (в том числе и медицинских), тесно связанных с высшими учебными учреждениями, Академией наук. Подготовка врачей из природных россиян являлась одной из важнейших задач времени, что обусловило возникновение новых медицинских факультетов университетов с необходимым созданием при них соответствующих учебно-вспомогательных структур. В их число входили медицинские кабинеты-музеи, лаборатории.

Первая половина XIX века в медицинском собирательстве определена нами как период «учебных коллекций» т. к. они преобладали среди других и оказывали значительное влияние на прочие музейные структуры. Параллельно с формированием коллекций в университетах, в фельдшерских школах широко было развито частное собирательство аристократией и представителями врачебного сословия. В этот период закладывались основы медицинской музейной деятельности, которые с незначительными изменениями существуют до настоящего времени. Одной из наиболее распространенных форм пополнения медицинских собраний стали дары. Мотивация к дарению была различна. Однако само дарение музеям постепенно стало традицией, не прерывающейся и в XXI веке.

3 Бурлыкина М. И. Музеи высших учебных заведений дореволюционной России (1724-1917 гг.). - Сыктывкар: Изд-во Сыктывкарского гос. университета, 2000. - 238 с.; Назипова Г. Р. Музейные функции учебновспомогательных учреждений Казанского университета (XIX - начало ХХ вв.) // Вестник РГГУ: Серия «Культурология. Искусствоведение. Музеология», 2009; 15: 283-291.

4 Виксна А. А. О выявлении и сохранении историко-медицинских памятников/А. А. Виксна, А. В. Дирбе, А. К. Звиедре// Советское здравоохранение, 1973; 8: 73-75; Васильев К. Г. Проблема источниковедения в истории медицины и музейном историко-медицинском деле / К. Г. Васильев, Ю. П. Лисицын // Тез. докл. І съезда социалгигиенистов, организаторов здравоохранения и историков медицины Латвийской ССР. - Рига, 1984. C. $156-157$. 
Основным местом сосредоточения медицинских собраний того времени был кабинет-музей. В исследовании Т. Ю. Юреневой отмечается, что противопоставление терминов «кабинет» и «музей», употребляемых для обозначения естественнонаучных коллекций в европейской культуре, длилось достаточно долго. Постепенно словом «музей» стали обозначать не только коллекцию, но и помещение, в котором она находилась. Понятие «музей» характеризовало помещение, в стенах которого протекала творческая работа по изучению и представлению окружающего мира. ${ }^{5}$ В России термины «музей» и «кабинет» применялись для обозначения специальной части учебного кабинета (мацерационной) ${ }^{6}$ или коллекции, входящей в его состав - «физиологический музей анатомического кабинета», «минералогический кабинет музея естественной истории», «патологоанатомический кабинет анатомического музея» и т. д. Нерасчлененность понятий «музей» и «кабинет» в первой половине XIX века свидетельствует о том, что на русской почве традиции естественнонаучных кабинетов средневековья и эпохи Возрождения, включавших различные собрания, по отношению к медицинскими коллекциями были достаточно устойчивы.

Профессиональная деятельность врача проходит не только в кабинете, но также и в палатах и операционных, в учебных аудиториях, в лабораториях. Кабинет специалиста уже в процессе его использования кроме места занятий и раздумий его владельца имеет ещё одно свойство - особой зоны отдыха. В нем сосредоточены предметы искусства, любимые, дорогие и памятные для хозяина вещи, подарки от друзей, пациентов, коллег, составляющие уникальный, неповторимый интерьерный комплекс мемориального характера, в котором изначально заложена возможность новой трансформации превращение в музей.

Сохранилось интересное свидетельство об обстановке кабинета Ивана Федоровича Буша (1771-1843), автора первого в стране «Руководства по хирургии», вышедшего на русском языке в

5 Юренева Т. Ю. Музей в мировой культуре. - Москва: «Русское слово», 2003. - C. 133-134.

${ }^{6}$ Комната, где осуществлялся процесс мацерации, и изготавливались костные препараты и связные скелеты. 
1807 году, собирателя интересных предметов медицинского назначения: «В кабинете профессора находятся: шкаф с бандажами и моделью Вольфсона; несколько шкафов с инструментами и машинами; шкаф с глазными и зубными инструментами и литотрипсический стол», - писал в своем исследовании А. Ландшевский. ${ }^{7}$ Результатом пятидесятилетней деятельности И. Ф. Буша в стенах Императорской медико-хирургической академии (ИМХА), помимо прочих достижений, стало создание большого анатомического музея, часть предметов которого сохранилась до настоящего времени. Сам профессор активно участвовал в составлении необходимого ему для преподавания и практической деятельности инструментального комплекса, собрания натурных препаратов, рисунков, книг, располагая все в кабинете, который естественно превращался в музей, а его хозяин становился непроизвольным дарителем всего накопленного в нём.

Особого внимания заслуживает отношение Ивана Федоровича Буша к оснащению кафедры необходимым хирургическим инструментарием и аппаратурой. В 1802 году - пишет А. Ландшевский - Государственная Медицинская коллегия предложила дать конференции свое заключение по вопросу о приобретении Вольфсонова хирургического аппарата. Заключение конференции, подписанное профессором И. Ф. Бушем, гласило: «Сей аппарат нужен, как для обогащения хирургического кабинета, в пользу преподавания лекций, так и для некоторого украшения, приличного для сей Академии». Вульфсонов аппарат был приобретен и с высочайшего разрешения пожертвован в Виленский университет 18 января 1808 г. ${ }^{8}$

Своеобразным дарителем для медицинских музеев, отличавшимся большой щедростью, можно считать Медицинскую Канцелярию - орган государственного управления медицинским

7 Ландшевский А. Исторический очерк кафедры академической хирургической клиники Императорской Военно-медицинской (бывшей Медико-хирургической) академии (1798-1898) / Диссертация на степень доктора медицины. - СПб., 1898. - С. 113.

8 История Императорской Военно-медицинской (бывшей Медико-хирургической) академии за 100 лет 1798-1898 / Под ред. Н. П. Ивановского. СПб, 1898. - С. 113. 
делом в России в 1-й половине 18 века (1725-1763), реорганизованный в Медицинскую коллегию. ${ }^{9}$ Одновременно с решением насущных государственных задач по организации врачебной деятельности Медицинская Канцелярия выполняла функцию центрального хранилища, из которого все необходимое для педагогического процесса распределялось по учебным учреждениям или перераспределялось в связи с их упразднением. Например, среди раритетов, переданных из канцелярии в ИМХА, находились следующие предметы: коллекция Либеркюна, которая состояла из сухих, спиртовых и микроскопических препаратов; собрание анатомических препаратов графа Завадовского; часть коллекции инъекционных препаратов Ф. Рюйша, не вошедших в состав Кунсткамеры Российской Академии наук; значительная коллекция уродцев, которая собиралась в Медицинской Канцелярии на протяжении всего предшествовавшего столетия. ${ }^{10}$ По представлениям медицинской профессуры приобретались некоторые собрания и направлялись в учебные заведения. Например, у вдовы доктора медицины профессора Кнакстедта, скончавшегося в 1799 г., был приобретен Медицинской коллегией и передан впоследствии в ИМХА остеологический кабинет. Кнакстедтовский кабинет с остеологическими препаратами составлял одну из нескольких коллекций, которые предписывалось тщательно сохранять, ${ }^{11}$ так как, по завещанию последнего, он должен был использоваться в обучении студентов целиком, а не отдельными частями, чтобы обеспечить наглядность и высокий уровень преподавания анатомии как основы медицины.

Медицинская коллегия выпустила специальный циркуляр и постановила некоторые собрания, пожертвованные разными лицами содержать для памяти особо. ${ }^{12}$ Для данного периода стало

9 Медицинская коллегия - высший орган управления медицинским делом в России с 1763 по 1803 г.

10 Коровин И. Краткий исторический очерк кафедры патологической анатомии при Императорской Военно-медицинской (бывшей МедикоХирургической) Академии. - СПб., 1898. - С. 6-7.

11 Там же, с. 103.

12 Там же. 
типично появление в кабинетах-музеях предметов, которые имели особую мемориальную ценность. Например, кабинет профессора Ю. Х. Лодера (1753-1832) по распоряжению Александра I был куплен и целиком передан в Императорский Московский университет (ИМУ, 1820-е гг.). Собрание бережно сохранялось как свидетельство развития медицинской науки и врачебной практики и научных поисков известного врача. Эту коллекцию разместили в специальных шкафах, в особых комнатах и коридорах кафедры. Она была доступна для осмотра студентам.

Однако повода для подарка собрания первоначально не было. Личный кабинет ученого насчитывал немало ценных предметов и медицинских реликвий, которые он пожелал продать. В 1817 году президент ИМХА Я. В. Виллие составил комиссию из П. А. Загорского и профессоров академии для освидетельствования и оценки анатомического кабинета лейбмедика Ю. Х. Лодера, оценившего всю свою коллекцию в 139000 талеров. В таком подходе нет ничего корыстного, ибо изготовление препаратов из собрания, как и приобретение отдельных экземпляров, обошлось Ю. Х. Лодеру в весьма значительную сумму.

Что побудило его выступить с предложением о покупке коллекции? Он имел возможность предложить своё собрание любому университету Европы, но предпочел оставить его в стране, где служил много лет. Так при Ю. Х. Лодере численность всех экспонатов анатомического музея ИМУ в 1826 году составила 5000 препаратов.

Проволочки и затруднения в решении вопроса о приобретении лодеровского собрания тянулись довольно долго, и тогда он решил пожертвовать ее государю Императору Александру I. В коллекции находились ценные препараты, среди которых были скелеты человека и животных (87), племенные черепа (173), черепа животных (24), спиртовые препараты (300). Лодер занялся строительством анатомического театра по своему плану, безвозмездно читал лекции студентам в отстроенном новом здании. Деяния профессора были отмечены Орденом Св. Владимира и Орденом Св. Анны 2-ой степени с бриллиантами на рескрипте. Однако по сообщению профессора Н. Д. Зернова в конце XIX века из его коллекции уцелело очень 
немногое. 13 В отчете, составленном профессором И. М. Соколовым, в 1855 г. в анатомическом музее числились 6144 препаратов, а в 1868 - 7780. ${ }^{14}$ Рост собрания был обеспечен в основном за счет новых работ студентов и препаратов. Отдельные предметы из Лодеровской коллекции украшают коллекцию музея кафедры нормальной анатомии Первого Московского государственного университета им. И. М. Сеченова.

Пожертвования от императора и членов царской семьи, частных лиц значительно расширяли собрания медицинских кабинетовмузеев. ${ }^{15}$ В 1820 году Император Александр I приобрел коллекцию восковых патологических препаратов из Венской Иозефинской Академии. ${ }^{16}$ Как и приобретенные в 1765 году Екатериной II для преподавания медицины в учебных заведениях Санкт-Петербурга препараты и микроскопы Либеркюна. ${ }^{17}$ По личному распоряжению императора Павла I был приобретен архив знаменитого голландского ученого, ректора Лейденского университета Германа Бургаве (1668-1738) и его родственников - Германа Карла Бургаве (1705-1753) и Абрахама Каау Бургаве (1715-1758). ${ }^{18}$ Это приобретение явилось одним из ценных свидетельств о научной и практической работе врачей XVIII века, продолжением собирательства медицинских коллекций, начатого Петром I. Документы купили у наследников семьи Бургаве в конце XVIII века. Император Павел I пожелал, чтобы использовали и сохраняли архив в академии. Несколько сотен рукописей научных

13 Сапин М. Р. Профессора-анатомы и анатомический музей в ММА им. И. М. Сеченова: Медицинская профессура Российской Империи // Краткое содержание и тезисы докладов научной конференции 3 марта 2006 г. - Москва, 2006. - С. 183.

14 Там же.

15 История Императорской Военно-медицинской (бывшей Медикохирургической) академии за 100 лет 1798-1898 / Под ред. Н. П. Ивановского. - СПб., 1898. - С. 103.

16 Коровин И. Краткий исторический очерк кафедры патологической анатомии при Императорской Военно-медицинской (бывшей Медикохирургической) академии. - СПб., 1898. - С. 8.

17 История военной медицины в России: XVIII в. - Том 2. - СПб.: ВМедА, 2002. - C. 206.

18 Там же, с. 207. 
работ, лекций, писем, рецептов, истории болезни и другие материалы ныне хранятся в Фундаментальной библиотеке Военно-медицинской академии им. С. М. Кирова, как часть документов XVIII в. ${ }^{19}$ В таких целенаправленных приобретениях-дарах в медицинские музеи ИМХА и университетов, прослеживается сформировавшаяся традиция попечения образовательных учреждений и интереса к куриозностям, истоки которого уходят в Петровскую эпоху.

Историограф ИМХА приводит свидетельства об интересе к музейным медицинским коллекциям со стороны дарителей, доступности собраний просвещенной публике и посещении академии лицами царствующего дома.

«29 января 1806 г. из анатомического театра перенесли некоторые препараты для показания Государю (велено выставить разные любопытные вещи). 3 февраля Император при открытии академической клиники удостоил посещением своим академию. При прибытии Его Императорского Величества ректор И. П. Франк говорил речь на французском языке о пользе клинической больницы, потом показывал клинику, из которой, вышедши, держал пробную лекцию на латинском языке «De febre nervosa maligna». После сего Его Величество через актовую залу прошел в библиотеку, где, по осмотре анатомического кабинета Крюикшанка и во второй большой зале полученных книг из чужих государств, был дан завтрак». ${ }^{20}$

Дарителем выступил и президент ИМХА Я. В. Виллие. В 1809 году прозектор Яворский поднес президенту восковой препарат головы со вскрытым черепом и мозгом и с изображением положения внутренностей полости рта. Виллие подарил этот препарат академии, где он в несколько измененном виде и с утратой ряда деталей сохранялся до конца XIX века. ${ }^{21}$ В 1822 году наследники покойного коллежского советника доктора Циргольца передали анатомическому кабинету изображение человеческого скелета, вырезанное Бахерахтом из слоновой кости (в уменьшенном виде).

\footnotetext{
19 История военной медицины в России: XVIII в. - Том 2. - СПб.: ВМедА, 2002. - C. 207.

20 Там же, с. 107.

21 Там же, с. 49.
} 
Представители врачебного сословия безвозмездно жертвовали в музеи-кабинеты не только препараты, но и другие ценные памятники медицины. Условия хранения всех даров в ИМХА вместе в одном анатомическом музее, расположенном в небольшом и тесном помещении, затрудняли их размещение по научному принципу, ${ }^{22}$ описание и подготовку каталога, что удалось преодолеть лишь с постройкой нового анатомо-физиологического корпуса и созданием Хирургического музея во второй половине XIX в.

Собирателями медицинских раритетов являлись преимущественно сами врачи. Как справедливо отмечала Д. А. Равикович «значение частного коллекционирования в данный период состоит, прежде всего, в формировании фонда национальных культурноисторических ценностей. Кроме того, все более широкое распространение собирательской деятельности создавало особую атмосферу в обществе, необходимые предпосылки для образования позднее собственно музейных собраний». ${ }^{23}$ Собирательство медицинских памятников имеет свои особенности - в основу этой деятельности положен научный интерес специалиста, профессионала.

Показателен в этом аспекте «Кабинет И. В. Буяльского» - частное собрание анатомических, патологических препаратов; хирургических, анатомических и акушерских инструментов заслуживает особого внимания. Собиралась эта коллекция около полувека и в нее вошли замечательные предметы из всех частей света, частью присланные в дар профессору И. В. Буяльскому (1789-1866) иностранными учеными, ценившими его хирургические заслуги, частью приобретенная покупками от лучших мастеров Европы. Любя анатомию и хирургию, профессор собирал все, что представляло поступательный ход этих наук, так что коллекция его могла служить наглядной историей их развития. Всех предметов в этом кабинете около 3000. Каталог коллекции И. В. Буяльского был составлен им самим и опубликован в 1854 году. В истории

22 История военной медицины в России: XVIII в. - Том 2. - СПб.: ВМедА, 2002. - С. 16.

23 Равикович Д. А. Музейные деятели и коллекционеры в России (XVIII - нач. XX в.) // Музееведение: Концептуальные проблемы музейной энциклопедии. - Сб. науч. тр. НИИ культуры. - Москва, 1990. - С. 19. 
медицинских музеев и коллекций России этот труд является первым научным и систематическим описанием историко-медицинского собрания. На склоне лет академик, действительный статский советник И. В. Буяльский передал всю свою коллекцию, которая формировалась на протяжении его жизни, в дар ИМХА. Он считал, что в воспитании молодых врачей его собрание не будет излишним, а напротив, послужит умножению славы русской медицины.

Руководитель терапевтической клиники ИМУ Александр Иванович Овер (1804-1864), знаменитый московский практик и человек с большими дарованиями, занимался патологоанатомическими исследованиями и собрал материал для своего музея и атласа. ${ }^{24}$ В 1846 г. А. И. Овер решил обнародовать огромный материал, собранный им за 17 лет деятельности, особенно атлас, рисунки которого были сделаны художником Щеголевым. 25 Частично его коллекция сохранилась на кафедре патологической анатомии Первого МГМУ им. И. М. Сеченова.

Среди провинциальных собирателей медицинских памятников особое место занимает профессор терапии, патологии и клиники, а также естественной истории и ботаники Казанского университета К. Ф. Фукс (1776-1846), страстный поклонник поэзии и музыки, любитель естествознания, литературы, языкознания. Естественнонаучные коллекции профессора были обширны, современники подчеркивали, что особенно богаты минералогическая, зоологическая и ботаническая части собрания. В 1837 году университетом была закуплена за 1500 рублей ассигнациями его коллекция чучел животных и птиц в количестве 596 предметов. ${ }^{26}$ Профессор заложил основу новых музеев в составе учебно-вспомогательных учреждений Казанского университета: зоологического, зоотомического, минералогического, ботанического, использовавшихся в изучении медицины.

24 Скороходов Л. Я. Краткий очерк истории русской медицины. - Ленинград: «Практическая медицина», 1926. - С. 100.

25 http://www.biografija.ru/show_bio.aspx?id=99238

26 Назипова Г. Р. Музейные функции учебно-вспомогательных учреждений Казанского университета (XIX - начало XX вв.) // Вестник РГГУ: Серия «Культурология. Искусствоведение. Музеология», 2009; 15: 297. 
Частные коллекции медиков в первой половине XIX в., о чем свидетельствуют приведенные выше факты, органично вошли в состав медицинских кабинетов-музеев, будучи подарены самими владельцами или переданы через посредников (например, в случае с Ю. Х. Лодером таким посредником стал сам император России).

В рассматриваемый период в России происходило дальнейшее развитие историко-медицинских коллекций, которые рассматривались современниками как значимые, требующие сохранения для потомков научные и культурные ценности. Развитие этого процесса во многом было обусловлено передачей в дар музеям редких предметов медицинского назначения, которые приобрели статус музейного предмета. Дарение, как отдельных предметов, так и целых коллекций является важным стимулом для российского общества в создании музеев различного профиля, прежде всего общедоступных.

\section{Dāvinājumi un dāvinātāji Krievijas medic̄nas muzejiem 19. gadsimta pirmajā pusē}

\section{Kopsavilkums}

Medicīnas muzeju rašanās Krievijas impērijā, to krājumu veidošana un papildināšana ir jautājumi, kas līdz šim maz piesaistījuši pētnieku uzmanību.

Muzeju dibināšana Krievijā sāka izvērsties 18. gadsimtā, un tā saistīta ar cara Pētera I jaunievedumiem. Šajā laikā attīstījās muzejniecība, lielāka uzmanība tika pievērsta dabaszinībām, veidojās saikne starp muzejiem un augstskolām. Vietējo mediķu izglītošanas vajadzībām augstskolās tika veidotas dažādas papildu struktūras, t. sk. arī kabineti-muzeji.

19. gadsimta pirmā puse medicīnas muzeju vēsturē iezīmējās kā "mācību kolekciju” veidošanas posms. Eksponāti tika vākti universitāšu un feldšeru skolu vajadzībām, taču veidojās arī privātas kolekcijas, galvenokārt kā ārstu un dažu aristokrātu aizraušanās. Šajā laikā sākās arī dāvināšanas tradīcija. 
Tieši ārstu kabinetos krājās ne tikai ar ārstniecību saistītās lietas, bet ar̄̄ mākslas priekšmeti, piemiņas lietas, pacientu dāvinājumi. Te veidojās kolekcijas, kas vēlāk ieguva muzejisku vērtību, piemēram, Imperatora ķirurǵiskās akadēmijas profesora I. Buša kabineta iekārtojums, instrumenti, lietas un dokumenti kḷuva par anatomijas muzeja pamatu, pateicoties kabineta saimnieka dāsnajam dāvinājumam.

Bagātīgus dāvinājumus (sevišksi - anatomiskos, t. sk. osteologiiskos, eksponātus) medicīnas muzeji saņēma arī no Medicīnas kancelejas valsts institūcijas, kas 18. gs. pirmajā pusē Krievijā pārraudzīja medicīnas nozari un ko vēlāk pārdēvēja par Medicīnas kolēǵiju. Valsts arī nopirka vairāku izcilu mediķu kabinetus ar visu iekārtojumu, lai saglabātu šīs vērtīgās laikmeta liecības. Interesi par medicīnu, tās mācīšanu un vēsturi izrādīja un ziedojumus krājumu iegādei atvēlēja arī cara ǵimene, piemēram, Aleksandrs I 1820. gadā no Vīnes Jozefa akadēmijas iegādājās vaska eksponātus, kas atainoja dažādas patoloǵijas, savukārt Katrīna II Sanktpēterburgas medicīnas mācību iestādēm sagādāja preparātus, mikroskopus u. c. lietas.

Muzejisko vērtību krājumi auga, tos regulāri papildināja arī pašu mediķu dāvinājumi (I. Bujaļina, A. Overa, K. Fuksa u. c.). Lai savāktās vērtības varētu zinātniski apstrādāt, kataloǵizēt, izstādīt, 19. gs. otrajā pusē tika izveidots Ķirurğijas muzejs. Ārstu kolekcijas veidoja pamatu arī citu dabaszinātņu muzeju izveidošanai.

\section{Gifts and Donators of Medical Museums in Russia in First Half of the $19^{\text {th }}$ Century}

\section{Abstract}

In the article the problem of gifts and structure of donators to medical museums in Russia in the first half of the $19^{\text {th }}$ century is considered as one of the factors of formation of scientific collections.

From museums of an epoch of Peter the Great to museums of the Academies of Sciences and Universities phenomenal gifts, motivation of donators and destiny of separate gifts is traced. The first half of the $19^{\text {th }}$ century has been named the period of "educational collections". This is 
the time when museum activity was incorporated as the basis in medical sphere, having been kept to this day with minor alterations. Gradually the tradition has grown to give gratuitous gifts to a museum, which has not been interrupted in the $21^{\text {st }}$ century.

Cabinet-museum then was the place where medical assemblies were kept. In Russia terms "museum" and "cabinet" were applied as synonyms. In a cabinet of a scientist (doctor), the opportunity of new transformation transformation into a museum is incorporated. The cabinet of Professor Bush I. F. in Imperial Medical-Surgical Academy has been filled by tools, books, figures, painting. It served as the basis for establishing an anatomic museum - Cabinet of Academy. Ivan Fedorovich has presented all his property to the Cabinet for training youth.

Gifts in museums were given by officials of Medical Board. Officials in representation of professors bought private collections and transmitted them in educational institutions. Thus increasing the collections of cabinets-museums and creating new ones. Transfer of gifts was held in memory of the known professor, at his desire or at will of relatives who carried out the last will of the donator.

Donations from the emperor and members of imperial family, private persons filled up assemblies of medical cabinets-museums. In 1820, Emperor Alexander I provided a collection of wax pathological preparations from vein. In 1765, Jekaterina II obtained and presented a plentiful of preparations and microscopes Lieberkuehn for teaching medicine in educational institutions of St. Petersburg.

Among private collectors at the time became many doctors. Academician Bujalsky I. V., Professors Over A. I. and Fuks K. F., known collectors and donators simultaneously. As a motive of their activity served the desire to maintain medical museums-cabinets as unique monuments as structurally organised unirs; thus serving as substantiated history of medicine.

\footnotetext{
Мария Павловна Кузыбаева, к. м. н. НИИ Истории медицины Российской академии наук, Москва kuzibaeva@inbox.ru
} 